\section{Pensar por si e dizer o que pensa: o ensino da argumentação e a formação de sujeitos autônomos}

Thinking for yourself and speaking your mind: the teaching of argumentation and the formation of autonomous individuals

Glayci Kelli R. S. XAVIER (UFF) glaycikelli@yahoo.com.br

Sirley Ribeiro SIQUEIRA (UFF) sirley.ribeirosiqueira@gmail.com

Recebido em: 15 de out. de 2018. Aceito em: 15 de fev. de 2019.

\title{
00000000000
}

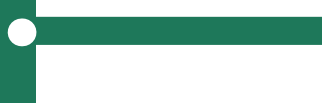

XAVIER, Glayci R. S.; SIQUEIRA, Sirley

Ribeiro. Pensar por si e dizer o que

pensa: o ensino da argumentação e

a formação de sujeitos autônomos.

Entrepalavras, Fortaleza, v. 9, n. 1, p.

72-92, jan-abr/2019.

Resumo: O ato de argumentar é uma prática essencialmente social e evidenciase em variadas ações cotidianas, nas quais se faz uso da linguagem, em suas diferentes atividades. Especificamente no ambiente escolar, sobretudo no Ensino Médio, a argumentação é assunto bastante explorado, principalmente nas aulas de produção textual, pois, para obter um bom resultado na redação do Exame Nacional do Ensino Médio (ENEM) e em vestibulares - grande objetivo da maioria dos alunos - é preciso dominar algumas técnicas argumentativas. A fim de que o trabalho com argumentação não se resuma ao ensino mecânico de modelos para obter sucesso em tais avaliações, e ancorando-se em uma perspectiva sociointeracionista, o presente trabalho procura mostrar que há outras formas de se trabalhar a argumentação na Educação Básica com o objetivo de formar cidadãos críticos: explorando os gêneros orais e os textos verbo-visuais presentes na mídia. Para isso, parte da experiência de dois projetos de iniciação científica que se inserem em um projeto maior desenvolvido pelas professoras, voltado para a leitura, análise e produção de gêneros argumentativos. Enfim, acreditamos que, ao oferecer subsídios 
que possibilitem aos alunos vivenciar as diferentes modalidades de leitura e produção, poderemos contribuir para a formação de cidadãos que saibam expor suas opiniões e que sejam capazes de ter uma efetiva participação na vida social.

Palavras-chave: Argumentação. Oralidade. Verbo-visualidade.

Abstract: The act of arguing is an essentially social practice and it is evident in a variety of everyday actions, in which language is used in different activities. Specifically in the school environment, especially in High School, the argumentation is a subject enough explored, mainly in textual production classes, because, to obtain a good result in the essay of the Brazilian National Secondary School Examination (ENEM) and in other college entrance exams - great objective of the majority of students - it is necessary to master some argumentative techniques. In order that the teaching of argumentation is not restricted to some mechanical models to be successful in such evaluations, this paper, based on a socio-interactionist perspective, intends to show that there are other ways of teaching argumentation in Basic Education, with the purpose of forming critical citizens: exploring the oral genres and the verbalvisual texts present in the media. For this, it presents the experience of two Scientific Initiation projects that integrate a larger project developed by teachers, aimed at reading, analyzing and producing argumentative genres. Finally, we believe that by offering subsidies that enable students to experience the different reading and text production modalities, we can contribute to the formation of citizens who can express their opinions and who are able to participate effectively in social life.

Keywords: Argumentation. Orality. Verb-visuality.

\section{Palavras iniciais}

A argumentação sempre foi objeto de estudo, desde a Antiguidade Clássica. De acordo com Charaudeau (2009, p. 202), os gregos já eram conscientes de que "ter influência sobre outrem" não era somente inerente à razão, pois o ser humano é igualmente feito de paixões. Desde aquela época, distinguia-se o que derivava da pura razão (ratio), daquilo que derivava da "interação dos espíritos", para a qual devia existir uma técnica expressiva suscetível de "comover e captar" o interesse de um auditório. Para Grize (apud CHARAUDEAU \& MAINGUENEAU, 2004, p. 52), a argumentação é "uma atividade que visa a intervir sobre a opinião, a atitude, e mesmo sobre o comportamento de qualquer indivíduo", por intermédio do discurso.

Segundo Charaudeau (1992, p. 785), a argumentação é uma totalidade que o modo de organização argumentativo contribui para construir. É, portanto, o resultado textual de uma combinação entre diferentes componentes que dependem de uma situação que tem uma finalidade persuasiva. Menezes (2006) ressalta que

[...] a partir do momento em que argumentamos acerca de um objeto do mundo, estamos agindo sobre alguém, buscando inseri-lo em um quadro específico de crenças e convicções 
V. 9 (1)

72-92

jan-abr

2019 possíveis no interior de uma determinada comunidade de fala. Quer dizer, além do aspecto quantitativo das relações argumentativas no cotidiano, ressalta-se sua constitutividade como fator fundamental na formulação de convergências, na articulação e rearticulação de vínculos da vida social (MENEZES, 2006, p. 87).

Com relação ao ambiente escolar, principalmente no Ensino Médio, a argumentação é objeto de estudo frequente, pois, para obter uma boa avaliação na redação do ENEM, é preciso dominar algumas técnicas argumentativas. Entendemos, entretanto, que este não pode ser seu maior objetivo. Conforme aponta Ducrot (apud KOCH, 1998, p. 29), a argumentatividade está inscrita na própria língua e, mesmo quando narramos ou descrevemos, em maior ou menor grau, fazemos uso de estratégias argumentativas.

Por isso, o presente trabalho, ancorando-se em uma perspectiva sociointeracionista, pretende mostrar outras perspectivas para o ensino da argumentação, de modo que o aluno possa desenvolver outras habilidades: a expressão oral e a leitura de textos verbos-visuais. Nesse sentido, parte da experiência de dois projetos de iniciação científica ${ }^{1}$ que se inserem em um projeto maior desenvolvido pelas professoras, voltado para a leitura, análise e produção de gêneros argumentativos.

\section{Argumentação: alguns fundamentos}

Argumentar é uma atividade discursiva que depende das representações socioculturais compartilhadas pelos membros de um determinado grupo, seja pela experiência ou pelo conhecimento. $\mathrm{O}$ engajamento do sujeito argumentante em face dessa verdade depende do olhar do outro (seu interlocutor).

Do ponto de vista discursivo-situacional, portanto, a argumentação depende do sujeito que argumenta e da situação em que este se encontra diante do interlocutor a que está ligado por um contrato de comunicação. O contrato é "a condição para os parceiros de um ato comunicativo se compreenderem minimamente e poderem interagir", promovendo juntos a construção do sentido, que é a meta essencial de qualquer ato de comunicação (CHARAUDEAU; MAINGUENEAU, 2004, p. 130).

\footnotetext{
${ }^{1}$ Informamos que todos os procedimentos foram realizados em conformidade com as normas institucionais e que foram atendidas as exigências da Resolução nº 510, de 7 de abril de 2016, referente a pesquisas envolvendo seres humanos.
} 
Nesse cenário, a construção argumentativa consiste, para o sujeito argumentante, na utilização de diversos procedimentos que servirão para cumprir sua intenção de comunicação, em função da situação e de como este percebe o seu interlocutor. Assim, para que haja argumentação, segundo Charaudeau (2009, p. 205), é necessário que exista:

- uma proposta sobre o mundo (tese) que leve alguém a um questionamento, quanto à sua legitimidade;

- um sujeito (sujeito argumentante) que se engaje em relação a esse questionamento (convicção) e desenvolva um raciocínio para tentar estabelecer uma verdade (quer seja própria ou universal, quer se trate de uma simples aceitabilidade ou de uma legitimidade) com relação a essa proposta;

- um outro sujeito (sujeito-alvo) que, ligado à mesma proposta, questionamento e verdade, constitui o alvo da argumentação. É a pessoa a quem se dirige o sujeito que argumenta, na esperança de que ele compartilhe a mesma verdade (persuasão), sabendo que ela pode aceitar (ficar a favor) ou recusar (ficar contra) a argumentação.

A argumentação, ao tentar influenciar esse outro, tende a um ideal de persuasão, a fim de fazer que o interlocutor compartilhe um certo universo de discurso e torne-se um coenunciador (em que o interlocutor é levado a ter as mesmas propostas). Isso pode ser obtido por meios diferentes formas de raciocínio, como por exemplo, pelos meios da sedução emprestados de outros modos de organização discurso (descritivo e narrativo).

Para atingir tais objetivos, o sujeito argumentante se entrega a uma tripla atividade cognitiva, que consiste em (CHARAUDEAU, 2004, p. $38-40)$ :

- problematizar uma certa asserção, com o intuito de fornecer ao interlocutor o meio (mais ou menos explícito) de determinar o quadro de questionamento ao qual é preciso ligar o ato de asserção. Corresponde a fazer saber não somente aquilo de que se trata a questão, mas também o que se deve fazer sobre isso; 
v. 9 (1)

72-92

jan-abr

2019

- elucidar a questão, de modo que o fato possa ser verificado, e que sua existência não seja posta em questão. Não se trata de provar a autenticidade do fato, mas de explicar o porquê e o como do fato. Diz respeito a fazer compreender as razões que são admitidas por hipótese, para explicar o estado do fato asseverado ou as consequências possíveis deste sobre acontecimentos futuros;

- provarasuatese, por meio de argumentos que desempenhem um papel de garantia de raciocínio e forneçam ao interlocutor os meios de julgar a validade do ato de elucidação que foi instaurado a partir da problematização inicial. Corresponde a um fazer crer que serve para fundamentar o valor de uma elucidação.

Charaudeau (1992, p. 803) ressalta que um processo argumentativo não deve ser confundido com uma simples asserção ("Eu bebo água"), nem com um simples encadeamento lógico de duas asserções ("Eu bebo água para emagrecer"). Para que tal processo se desenvolva, é necessário que o sujeito argumentante tome posição com relação à veracidade da proposta e que diga por que está de acordo ou não, ou tente provar a veracidade de sua proposta.

Enfim, todo ato de linguagem só tem significado em função da situação de comunicação na qual ele é produzido, da identidade e da intencionalidade do sujeito responsável por tal ato de linguagem, do tema de que trata (a tematização) e das circunstâncias materiais em que ele se encontra. A argumentação é, portanto, considerada uma prática social (ordinária ou erudita) na qual o sujeito que quer argumentar se encontra restringido pelos dados da situação comunicativa a que se subordina e, ao mesmo tempo, livre para jogar com essas restrições, sendo possível realizar seu próprio projeto de fala e trabalhar estratégias (CHARAUDEAU, 2004, p. 37, 44).

Consequentemente, não podemos afirmar que existiria uma forma ideal de argumentar, já que tal ato só pode ser julgado e validado em função de imposições da situação de comunicação e do projeto de fala. Da mesma forma, não podemos dizer que um texto é unicamente argumentativo, visto que os textos são plurais e contêm tipos discursivos diversos. Tais aspectos são importantes e não devem ser ignorados ao se ensinar sobre argumentação, de modo a evitar a produção mecânica de textos "pré-moldados". E é, justamente, o trabalho com a argumentação no ambiente escolar que abordaremos a seguir. 


\section{Argumentação: diferentes perspectivas de ensino}

Aprender a argumentar é a pedagogia mais profunda da vida do estudante, porque ele constitui-se, ao mesmo tempo, pesquisador e cidadão. (...) Não basta apenas expô-lo aos gêneros argumentativos, uma vez que para que ele compreenda de que maneira se constrói a argumentação dentro de cada texto, faz-se necessário que o professor o oriente a levá-lo a identificar o tema abordado, as condições em que o discurso é produzido e o modo como o autor constrói a argumentação em relação ao gênero utilizado (DEMO, 2000).

De acordo com os PCN de Língua Portuguesa (BRASIL, 1998, p. 54), o leitor competente é aquele que compreende o que lê; é aquele que percebe não só o que está escrito, mas identifica elementos implícitos; além disso, é aquele que estabelece relações entre o texto que lê e os outros já lidos, sabe que vários sentidos podem ser atribuídos a um texto, e consegue justificar e validar a sua leitura a partir da localização de elementos discursivos. Este amadurecimento, por sua vez, é fruto de uma prática constante de leitura de textos de diferentes gêneros.

Por meio de diferentes atividades de leitura, o aluno pode observar como os textos são construídos e isso influencia na forma como eles produzem seus próprios textos. Garcez (2004, p.23) afirma que, pela leitura, interiorizamos as estruturas da língua, os gêneros, os tipos de texto (modos de organização do discurso), os recursos estilísticos com mais eficácia do que pelas aulas e exercícios gramaticais. Portanto, a leitura ajuda a escrever melhor.

Em geral, os gêneros predominantemente argumentativos tratam da discussão de problemas sociais controversos e envolvem sustentação, refutação e negociação nas tomadas de posição. Dentre estes, podem-se citar: textos de opinião, diálogo argumentativo, carta de leitor, carta de reclamação, debate regrado, editorial, resenhas críticas, etc. Fica evidente, portanto, que a argumentação está presente nas mais variadas situações do nosso dia a dia. Apesar de ser uma linguagem complexa, nossos alunos estão envolvidos nessa complexidade e, mesmo que não seja conscientemente intencional, fazem uso de mecanismos de persuasão frequentemente.

O entendimento da relação leitura/escrita mostra que a escola deve diversificar as práticas de leitura e produção textual, oferecendo situações que estejam relacionadas às necessidades de uso da linguagem, assim como acontece na vida cotidiana, além de promover 
v. 9 (1) 72-92 jan-abr 2019

a reflexão sobre os diversos gêneros e usos da língua. Para que isso ocorra, o professor precisa promover projetos pedagógicos que visem ao conhecimento e também à leitura, além de fomentar a discussão sobre o uso, as funções sociais dos gêneros escolhidos, sua composição, seu estilo etc.

Concordamos com Menezes (2006, p. 87) quando afirma que "o ensino da argumentação pode levar a performances mais interessantes e democráticas na convivência social e política". Para isso, é preciso organizar o planejamento pedagógico de forma que o aluno possa vivenciar as diferentes modalidades de leitura e produção: ler e escrever para informar-se, estudar, revisar o que produz, para resolver problemas do cotidiano, para divertir-se, enfim, para agir no mundo. Assim sendo, a elaboração de projetos didáticos para a apresentação de determinado gênero textual, possibilita tomar o texto como "ponto de partida" e "ponto de chegada" do processo de ensino/aprendizagem de língua materna (GERALDI, 1995, p. 135) e apresenta-se como uma possibilidade bastante interessante de se trabalhar a produção de gêneros predominantemente argumentativos, sejam eles orais ou escritos.

Menezes (2006, p. 87) comenta que, no que diz respeito ao ensino, a argumentação é um campo ainda coberto de nebulosidade, já que, apesar de os próprios PCN destacarem a importância do estudo centrado no discurso/texto, a opção explícita pelo trabalho com a argumentação só se dá em momentos específicos, como se o seu estudo apenas em uma ou outra fase de formação fosse suficiente.

Outra falha da escola com relação ao ensino de produção textual é o fato de desconsiderarem a produção de textos orais, privilegiando somente a produção de textos escritos. De acordo com Marcuschi (1997),

A fala é uma atividade muito mais central do que a escrita no dia a dia da maioria das pessoas. Contudo, as instituições escolares dão à fala atenção quase inversa à sua centralidade na relação com a escrita. Crucial neste caso é que não se trata de uma contradição, mas de uma postura (MARCUSCHI, 1997, p. 39).

Os PCN (BRASIL, 1998, p. 43), por sua vez, afirmam que, quando se diz que a finalidade do ensino de Língua Portuguesa é "a expansão das possibilidades do uso da linguagem, assume-se que as capacidades a serem desenvolvidas estão relacionadas às quatro habilidades básicas: falar, escutar, ler e escrever". Assim, com o intuito de desenvolver tais habilidades e, com foco no ensino da argumentação, as professoras 
autoras desse trabalho elaboraram o projeto "Ponto de Vista", voltado para o ensino de gêneros predominantemente argumentativos, orais e escritos. As oficinas são direcionadas a alunos do Ensino Médio do Colégio Pedro II, no Rio de janeiro. Tal projeto visa à formação de cidadãos críticos, que saibam se expressar na sociedade em que vivem. Como desdobramento desse projeto, as professoras exploram a argumentação em grupos de iniciação científica júnior, especificamente em dois aspectos não muito explorados na escola: a oralidade e a verbovisualidade. Esses dois aspectos serão focalizados a seguir.

\section{Argumentação e oralidade: dizendo o que se pensa}

Em qualquer cultura, é por meio da fala que são realizadas a maior parte das atividades interacionais. Entretanto, a julgar pelo espaço dedicado à oralidade em muitos materiais didáticos, não tem sido dada a devida relevância à modalidade oral, embora sua primazia sobre a língua escrita há muito tenha sido reconhecida. Esta constatação, por outro lado, já presente em Marcuschi (1986), Koch (1996), Castilho \& Basílio (1996) e Castilho (1998), têm-nos motivado a buscar práticas educativas pautadas no desejo de contribuir para que o aluno, especialmente aquele que procede de um meio pouco letrado, possa escolher a variedade linguística adequada a cada situação e, ao assumir a palavra, defender seu posicionamento. Tendo em vista tais ideais de formação cidadã, participamos da criação de uma Sociedade de Debates, projeto desenvolvido com alunos do Ensino Médio, sobre o qual discorreremos mais adiante.

Partimos do entendimento de que a argumentação é uma necessidade da vida social e profissional e que, portanto, não pode ficar restrita à aprendizagem de técnicas para elaboração de uma boa dissertação, como se fazia antigamente, a fim de se alcançar um bom desempenho em exames oficiais, conforme já dissemos. São inúmeras as razões pelas quais a escola deve buscar contribuir para o desenvolvimento de habilidades que precisam ser mobilizadas durante a argumentação. Tais habilidades, contudo, não devem estar limitadas apenas ao texto escrito. É imperativo que, se a escola se propõe a preparar o aluno para a vida e para o mundo do trabalho, também dê a devida relevância ao ensino da língua oral, especialmente em situações em que se requer maior formalidade. 
v. 9 (1) $72-92$ jan-abr 2019

A título de exemplificação acerca da importância de saber como se expressar adequadamente na modalidade oral, basta lembrarmos que em nossa sociedade, muitas entrevistas de emprego feitas em grupo exigem que o candidato seja capaz de discutir um tema na frente dos outros candidatos e dos avaliadores; ou ainda, já empregado, que seja capaz de promover um produto ou apresentar e defender uma ideia que vá resultar em benefícios para a empresa na qual trabalha. A lista de exemplos em que o diálogo e a aptidão para convencer são pontos essenciais é bem mais extensa, entretanto, o que foi dito parece-nos suficiente para mostrar o quanto é importante dar relevância ao ensino da argumentação em gêneros orais.

Há, pelo menos duas décadas, conforme já apontamos, documentos oficiais como os Parâmetros Curriculares Nacionais (PCN) já preconizam o trabalho sistemático com a oralidade, dada a sua importância para a plena participação cidadã:

\begin{abstract}
Ensinar língua oral deve significar para a escola possibilitar acesso a usos da linguagem mais formalizados e convencionais, que exijam controle mais consciente e voluntário da enunciação, tendo em vista a importância que o domínio da palavra pública tem no exercício da cidadania (BRASIL, 1998, p.67).
\end{abstract}

Ancorados em pressupostos caros à Sociolinguística, os PCN também afirmam que:

a questão não é falar certo ou errado e sim saber que forma de fala utilizar, considerando as características do contexto de comunicação, ou seja, saber adequar o registro às diferentes situações comunicativas. É saber coordenar satisfatoriamente o que falar e como fazê-lo, considerando a quem e por que se diz determinada coisa (BRASIL, 1998, p. 69).

Em outras palavras, a orientação dos PCN remete a práticas voltadas para o ensino da língua falada de modo que fique clara, para os alunos, a existência de uma grande variedade de usos da fala. Tal variedade abrange, como se sabe, diferentes níveis, do mais coloquial ao mais formal. O desafio que nos é apresentado, portanto, diz respeito à ampliação da competência comunicativa na modalidade oral, de modo que os alunos adequem sua fala, considerando o interlocutor, o contexto e a situação.

Em meio a várias possibilidades de trabalho com gêneros textuais, capazes de contribuir para o aperfeiçoamento da fala em público formal, como o seminário, o júri simulado, a entrevista, dentre 
outros, escolhemos o debate devido ao seu caráter interacional e por desenvolver habilidades ligadas à elaboração de argumentos, ao mesmo tempo que exige atenção aos argumentos contrários ao seu ponto de vista. A seguir, discorreremos brevemente sobre tal gênero e apresentaremos uma proposta de prática de ensino, já em fase de implementação na educação básica.

\section{O gênero textual debate regrado}

O debate regrado, ou simplesmente debate, é um gênero predominantemente argumentativo, que se caracteriza pelo fato de uma pessoa, ou um grupo de pessoas, emitir opiniões divergentes acerca de um assunto polêmico. Diz respeito a uma variedade considerável de textos orais que circulam socialmente como: debate eleitoral, debate em sala de aula, em reuniões, em programas televisivos. Também pode aparecer em meio a conversas do dia a dia, entrevistas, apresentações de trabalhos acadêmicos, etc.

Vale lembrar que nem sempre houve o direito à expressão do pensamento e a possibilidade de veicular as próprias ideias em diversos meios. Sem dúvida, poder disseminar a sua opinião sem medo de cerceamento foi uma grande conquista das sociedades modernas, o que possibilitou, dentre outras ações, o estabelecimento do debate como um instrumento enriquecedor de nossa visão de mundo. Concordamos com Aquino (2015), para quem o debate pode se transformar numa ferramenta enriquecedora do trabalho com a oralidade. Segundo as palavras da autora:

\footnotetext{
O debate, além de contribuir para o desenvolvimento de habilidades necessárias às práticas sociodiscursivas determinadas, propõe-se que o ensino da argumentação nos gêneros orais se atenha à observação de estratégias selecionadas em interações na quais se destaque o jogo interacional que se delineia quando se busca persuadir os interlocutores (AQUINO, 2015, p. 227).
}

Afim de propiciarmosaos alunos do Ensino Médio a oportunidade de aperfeiçoarem a fala em público formal, criamos em nossa escola uma Sociedade de Debates, aberta a quaisquer alunos interessados (de diferentes séries do Ensino Médio) em aprender um pouco mais sobre defesa de ideias e elaboração de argumentos e contra-argumentos. A seguir, faremos uma breve descrição sobre como funcionam as Sociedade de Debates, as principais vantagens desse modelo e analisaremos alguns fragmentos de fala, representativos do corpus coletado. 
v. 9 (1) 72-92 jan-abr 2019
Uma Sociedade de Debates consiste em um grupo organizado de alunos debatedores e juízes e, geralmente, segue o padrão do Parlamento Britânico. Em tal modelo, há quatro duplas de debatedores que discutem a moção (recorte mais específico do tema estabelecido) dada no dia do debate. Também no dia do evento, os debatedores descobrem se terão que argumentar favoravelmente à moção ou se deverão apresentar argumentos contrários a ela, de modo que duas duplas fiquem, portanto, a favor e duas duplas sejam contrárias, formando-se duas bancadas de duas duplas cada. O primeiro debatedor a proferir o seu discurso pertence à bancada de defesa e o segundo, à bancada de oposição. Cada debatedor tem até sete minutos para apresentar seus argumentos.

Seguindo este padrão, também há alguns papéis prédefinidos a serem cumpridos pelos debatedores: o primeiro debatedor, da bancada de defesa, precisa fazer a definição da moção, ou melhor, escolher, dentre as palavras que compõem a moção, algumas delas para defini-las de modo a manter o recorte dado na moção e favorecer a sua bancada. O último debatedor de cada bancada tem a função de resumir os argumentos apresentados por sua bancada com o intuito de reiterar a relevância de tais argumentos e justificar por que os argumentos escolhidos foram os mais convincentes para a defesa de suas ideias.

A avaliação é feita por dois ou três juízes e julga a apresentação de argumentos acompanhados de referência, a oratória, a linha de raciocínio, a capacidade de responder as perguntas feitas e de refutar os argumentos da bancada oposta e, finalmente, de seguir as regras estabelecidas pelo modelo. Ao final do debate, os juízes declaram qual foi o melhor debatedor individual e qual foi a melhor dupla. Os juízes também precisam dar a todos os debatedores um feedback acerca do seu desempenho individual, baseando-se nos critérios anteriormente descritos. O papel de juiz, por isso, precisa ser desempenhado por um aluno mais experiente ou pelo professor.

Os temas escolhidos para os debates podem pertencer a quaisquer áreas de estudo. A definição antecipada do tema, feita de maneira democrática pelos alunos, faz com que o aluno tenha que pesquisar o maior número de informações possíveis para construir seus argumentos. Também vale lembrar, como já dissemos, que os debatedores só descobrem alguns minutos antes do debate se argumentarão contra ou a favor da moção. Por si só, isto já é um aspecto positivo porque os alunos são levados a se preparem tanto elaborando argumentos contrários, quanto a favor da moção. 
Aliás, a própria preparação para o debate merece destaque. Se desejamos que nossos alunos sejam cada vez mais autônomos e capazes de construir conhecimento, precisamos concebê-los como pesquisadores em potencial, especialmente no mundo em que vivemos, cujo acesso à informação está cada vez mais democratizado por meio da internet.

Outras vantagens que podem ser apontadas são que os alunos, ao participarem de debates, consolidam os conhecimentos já adquiridos por meio de pesquisas ou através das aulas, treinam a fala em público, defendem o seu ponto de vista por meio de argumentos, ouvem ideias diferentes das suas, buscam refletir a partir do ponto de vista do outro, exercitam a capacidade de contra-argumentação. Além destes aspectos positivos, não podemos deixar de mencionar o fato de que todos são orientados a manterem regras de cortesia e respeito, a fim de que a discussão sempre fique restrita ao campo das ideias.

A seguir apresentaremos a transcrição ${ }^{2}$ de alguns trechos de um debate realizado com os alunos do Ensino Médio, cujo tema foi "Agronegócio" e cuja moção, dada no dia, foi "Esta Casa é favorável à facilitação da liberação de novos agrotóxicos no Brasil". Para a transcrição das falas, seguimos as normas que aparecem em Castilho \& Preti (1986). Os fragmentos abaixo dizem respeito ao primeiro minuto de fala dos dois primeiros debatedores, um de defesa (L1) e outro de oposição à moção (L2), respectivamente:

L1 - boa tarde a todos presentes... a bancada... a caríssima bancada de...de defesa... e a caríssima bancada de oposição...a mesa de juízes e a toda a plateia que está presente aqui... esta casa é favorável à facilitação de novos agrotóxicos no Brasil... favorável seria o quê? o ponto positivo...os pontos favoráveis... os pontos que estão eh:: interagindo com a economia com a sociedade e que podem ser produtivos e a facilitação que seja mais inclusiva e que seja uma prática que seja cada vez mais frequente para... tanto para grandes agricultores quanto para pequenos produtores... eh::eu e minha caríssima dupla acreditamos que eh:: para ser inclusivo devemos também cuidar dos pequenos produtores... como? sabemos que os pequenos produtores equivalem a grandes números eh:: de porcentagem na agricultura brasileira... oitenta e sete por cento da mão de obra está na mão destes pequenos produtores... eh::

É interessante observar, em relação à fala de L1, que ele opta por usar um vocativo bastante formal para se referir às bancadas de oposição e defesa, com o propósito de projetar um discurso protocolar. É

${ }^{2}$ Temos procurado gravar o áudio de cada debate, a fim de acompanharmos a evolução dos alunos ao assumirem a palavra. 
v. 9 (1) 72-92 jan-abr 2019

possível perceber também que há uma preocupação em cumprir o papel esperado para o primeiro debatedor da bancada de defesa, que é o de definir a moção dada. Esta tarefa é feita nesse primeiro minuto de fala e o seu planejamento se dá simultaneamente à sua execução, de modo que é compreensível a presença de fáticos como "eh::", atuando como preenchedores de pausa, ou seja, funcionam como termos recrutados pelo falante enquanto processa cognitivamente o que pretende expressar. Vejamos agora também o primeiro minuto de fala do segundo debatedor:

L2 - olá bom dia a todos... bom dia aos...aos debatedores... bom dia à mesa... bom dia à belíssima plateia...venho aqui hoje falar sobre os agrotóxicos e o uso deles no Brasil... e... a oposição como a minha dupla... nós achamos que o uso de agrotóxicos no Brasil não é uma boa saída... não é uma boa solução... mesmo que isso alavancaria a produção de alguns agricultores... isso causaria como causa e temos dados que comprovam isso... isso causa algumas doenças em agricultores principalmente na produção familiar que são produções em menores escalas... elas causariam danos a... a quem tá ali com a mão na terra... quem tá no campo fazendo o seu trabalho... e essa pessoa esse homem... essa mulher... ele tem uma casa... ele têm uma família...

L2, por sua vez, adota um tom menos formal e, como não precisa mais definir a moção, expressa de maneira bastante objetiva o seu ponto de vista (nós achamos que o uso de agrotóxicos no Brasil não é uma boa saída). Após a elocução de sua tese, contudo, é feita uma observação (mesmo que isso alavancaria a produção de alguns agricultores) baseada na fala do debatedor anterior. Tal ressalva aparece justamente com o propósito de elaborar uma contra-argumentação, como se pode observar na sequência seguinte ("isso causa algumas doenças em agricultores principalmente na produção familiar que são produções em menores escalas"), que evidencia o caráter dialógico do debate. Em outras palavras, há uma investida feita por L2 com o intuito de desconstruir um dos argumentos usados por L1.

Poderíamos tecer outros comentários acerca das características inerentes ao texto falado e ao gênero debate a partir dos fragmentos acima apresentados. Entretanto as limitações de espaço deste trabalho nos levam a sumarizar nossas observações destacando a relevância de se trabalhar com o debate na Educação básica, uma vez que, por meio deste gênero, habilidades relacionadas à interação e ao uso estratégico de argumentos são ampliadas, além, é claro, de darmos oportunidade para que nossos alunos treinem a expressão oral em um contexto formal. Outra maneira de se trabalhar a argumentação numa perspectiva diferente da tradicional é a exploração de textos verbo-visuais, conforme veremos a seguir. 


\section{Argumentação e verbo-visualidade: pensando por si mesmo}

A leitura não deve ser considerada simplesmente uma decodificação de signos linguísticos. Como define Garcez (2004, p.23), a leitura é "um processo complexo e abrangente de decodificação de signos e de compreensão e intelecção do mundo que faz rigorosas exigências ao cérebro, à memória e à emoção" e que lida com "a capacidade simbólica e com a habilidade de interação mediada pela palavra". A autora ainda afirma que é um trabalho que envolve "signos, frases, sentenças, argumentos, provas formais e informais, objetivos e intenções, ações e motivações", ou seja, envolve especificamente os elementos da linguagem, mas também os da experiência de vida dos indivíduos. A partir dessa concepção, é possível afirmar que, ao analisar um texto, não só os dados linguísticos, mas os elementos extralinguísticos e não verbais devem ser considerados.

Conforme aponta Cagnin (2014, p. 28), "hoje nos vemos cercados de imagens por todos os lados, a todo o momento e em tal profusão que, nela engolfados, mais conhecemos a imagem das coisas do que as coisas da realidade". As imagens são portadoras de memórias, culturas e tradições. Elas podem transformar um instante em eternidade. Conjugando imagem à palavra, o potencial comunicativo de ambas é ainda ampliado, podendo uma reforçar o que diz a outra, dizer o que a outra não diz, ou mesmo desdizer o que é dito pela outra, criando diferentes efeitos de sentido. E, nessa relação, muitas vezes a argumentatividade é construída, sendo importante entender como se dá essa interação para compreender melhor muitos dos textos presentes na mídia.

Charaudeau afirma que o estudo da argumentação deve se concentrar sobre o modo pelo qual o discurso se organiza, não sendo, assim, reduzido a uma sequência de frases ou proposições ligadas por conectores lógicos. O autor ressalta isso quando diz que "o aspecto argumentativo de um discurso encontra-se frequentemente no que está implícito" (CHARAUDEAU, 2009, p. 204). Um exemplo citado por Charaudeau são os slogans publicitários que, por menos argumentativos que sejam em sua aparência, devem ser compreendidos em função do esquema argumentativo que define esse gênero de comunicação.

Sob essa perspectiva o projeto de Iniciação Científica Júnior "Argumentação in foco: análise de textos verbo-visuais presentes da mídia" foi elaborado. Por meio desse projeto, pretende-se que os educandos: 
v. 9 (1) 72-92 jan-abr 2019

- reconheçam que a argumentatividade está inscrita na própria língua e, mesmo quando narramos ou descrevemos, em maior ou menor grau, fazemos uso de estratégias argumentativas;

- compreendam que a argumentação pode aparecer em diferentes gêneros discursivos;

- reconheçam que, em um texto verbo-visual, os sentidos emergem das relações que se estabelecem entre a linguagem verbal e a visual;

- identifiquem os recursos linguístico-discursivos e as estratégias da argumentação presentes em diferentes gêneros da instância midiática.

Desse modo, o projeto tem como principal objetivo fornecer subsídios que levem os alunos a ler/interpretar/analisar diferentes textos veiculados pela mídia, textos em que a argumentação está presente, mas muitas vezes não claramente. São privilegiados os textos verbovisuais, já que o desenvolvimento da tecnologia e o grande acesso ao "mundo" virtual fazem com que a leitura de textos multimodais precise ser desenvolvida.

Primeiramente, foi feita a leitura e discussão de textos teóricos que abordassem: a argumentatividade presente em gêneros midiáticos como as tirinhas, as charges, os textos publicitários e as capas de jornal e revistas; os pressupostos e subentendidos; os argumentos implícitos; as estratégias de captação. Posteriormente, a professora, juntamente com os alunos, achou que seria mais produtivo, em um primeiro momento, selecionar o corpus de análise pelo tema abordado, em vez de focar um gênero específico.

O primeiro tema escolhido pelos alunos foi o "sistema de cotas". Os estudantes passaram, então, a pesquisar textos verbo-visuais presentes na mídia que tivessem relação com tal tema. Do material apresentado, foram selecionados 11 textos, de gêneros diversos. Esses textos foram numerados de 1 a 11 e os alunos deveriam analisar cada texto, referindo-se a seu respectivo número, dizendo se este era contra ou a favor o sistema de cotas e explicando que elementos da parte verbal e/ou visual fizeram com que chegassem a tal conclusão.

Desses 11 textos, serão demonstrados apenas quatro. Um exemplar contra e um a favor de cada gênero discursivo - dois textos em quadrinhos e duas capas de revista. Gêneros semelhantes com teses opostas foram colocados lado a lado com o objetivo de enriquecer a análise por meio da comparação. 
Figura 1 - Cotas nos esportes 1.
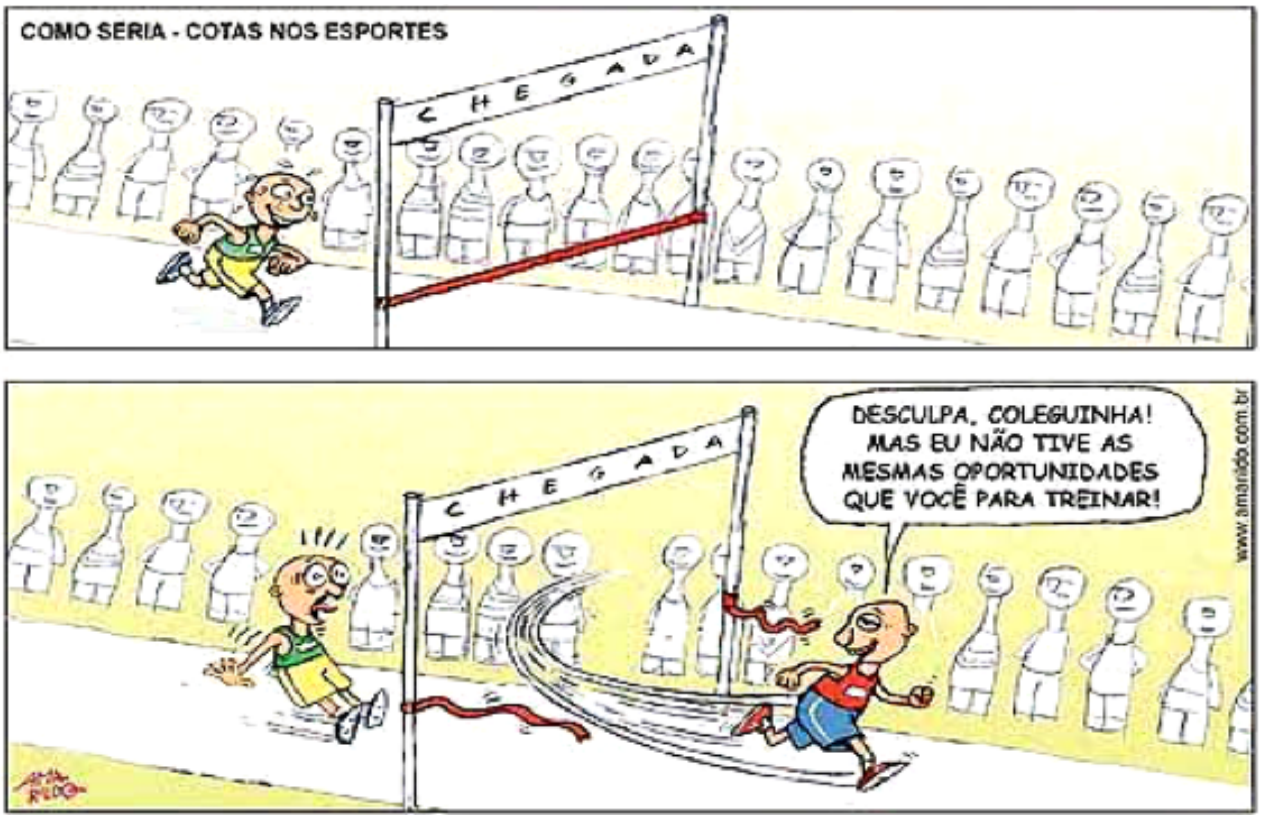

Fonte: http://www.emdialogo.uff.br/tags/cotas-nas-universidades. Acesso em: 16/09/2018.

Figura 2 - Cotas nos esportes 2.

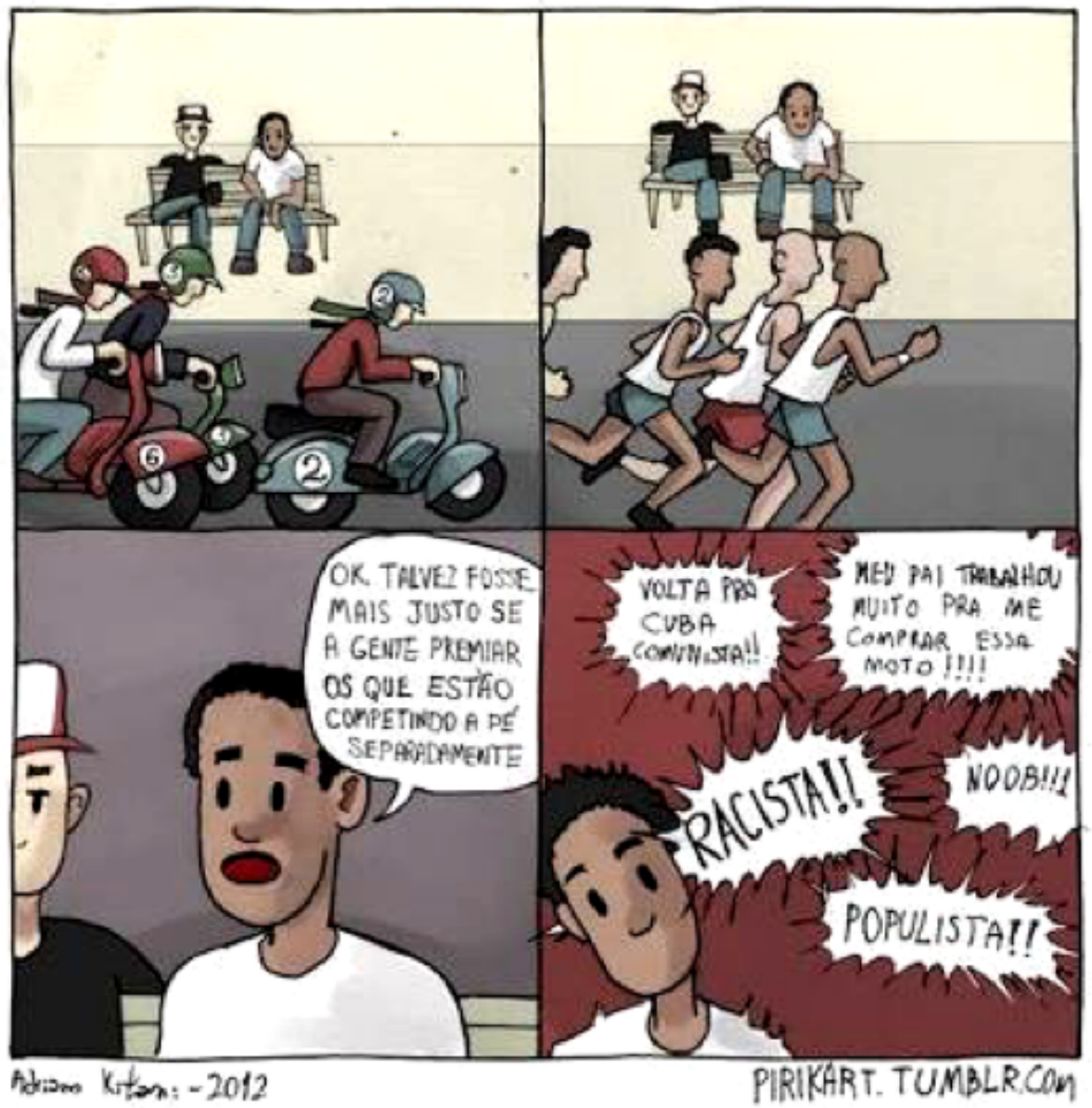

Fonte: https://www.cafecomsociologia.com/cotas-e-meritocracia/. Acesso em: 16/09/2018. 
v. 9 (1) 72-92 jan-abr 2019

As figuras 1 e 2 trazem textos em quadrinhos que fazem uma analogia entre sistema de cotas e as competições esportivas. Em uma primeira leitura já dá para perceber que a figura 1 é contra, enquanto a figura 2 é a favor das cotas.

Com relação à figura 1, os alunos apontaram os seguintes argumentos: 1) o texto diz nas entrelinhas que o cotista não se esforça tanto e ainda "sai na frente" dos não cotistas; 2) o texto passa um "ar" irônico de que as cotas "roubam" para aqueles que possuem menos oportunidades; 3) o texto debocha de um dos motivos pelo qual as cotas existem, que é a desigualdade de oportunidades e a tentativa de "facilitar" o acesso de pessoas menos favorecidas social e historicamente.

Pode-se perceber que, ao dizer que o cotista "sai na frente" e que o acesso foi "facilitado", eles observaram os elementos visuais dos quadrinhos. Quando falam de "oportunidades", observaram a parte verbal.

Já quanto à figura 2, foram destacados os seguintes argumentos: 1) o texto mostra uma pessoa que considera que a competição é injusta, por ter pessoas de moto, enquanto outros estão a pé, apostando uma corrida; 2) um competidor sugere uma separação de categorias para que os menos favorecidos possam competir de maneira justa; 3) o rapaz é "condenado" por achar que deveriam diferenciar os corredores, já que a oportunidade e as condições para a corrida não são iguais; 4) o texto faz uma analogia ao sistema de cotas, que existe justamente para tentar igualar as oportunidades e condições para um mesmo objetivo.

É possível verificar que parte não verbal da figura 2 foi analisada quando eles mencionam as pessoas apostando uma corrida, uns de moto, outros a pé. A parcela verbal complementa o sentido quando eles falam que um dos competidores sugere uma separação dos corredores por categorias e que o rapaz foi "condenado" por isso. A ideia de condenação é expressa por meio das frases "volta pra Cuba, comunista" e "meu pai trabalhou muito pra me comprar essa moto", mostrando a discordância das ideias apresentadas, além dos adjetivos ditos em tom pejorativo, como "racista", "populista" e "noob!!!" 3.

\footnotetext{
${ }^{3}$ Segundo o site "Dicionário popular", Noob ou Noob (com dois zeros) é uma gíria em inglês que significa "novato", muito utilizada em comunidades de jogos online para indicar o nível precário de jogabilidade de uma pessoa. Essa gíria pode ser entendida como um xingamento, pois remete a termos pejorativos, como "burro", "imbecil". Fonte: https://www.dicionariopopular.com/noob/. Acesso em: 10/10/2018.
} 


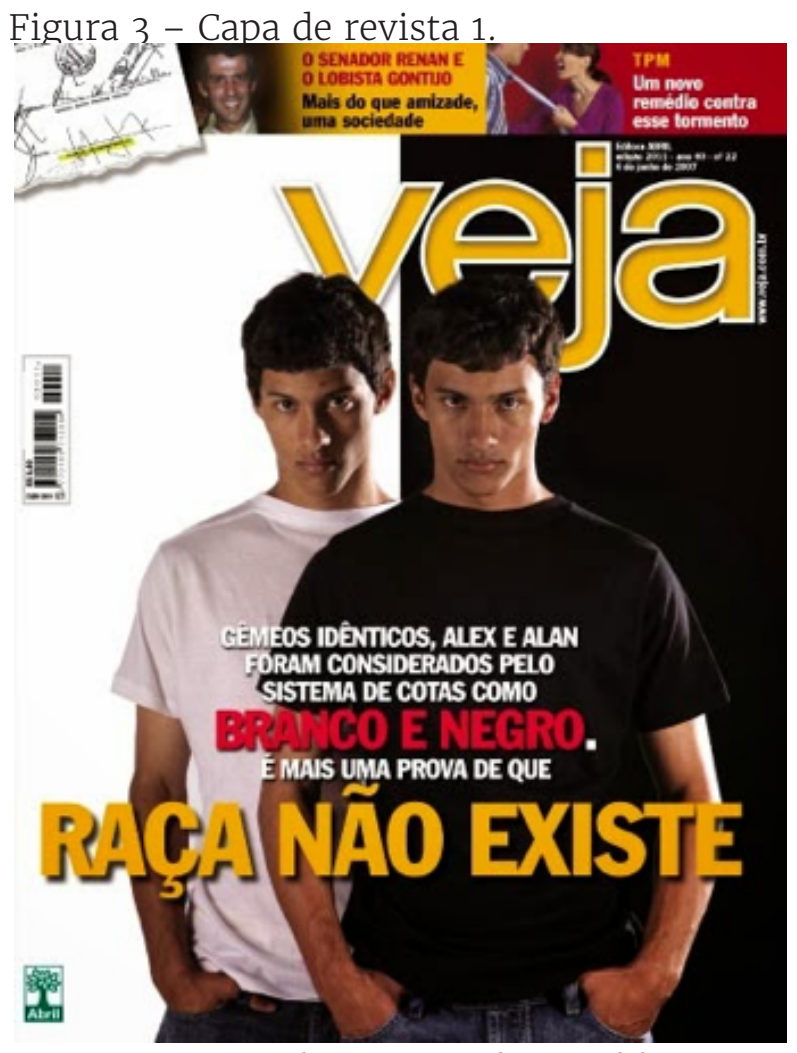

Fonte: http://exnelnegra.blogspot. $\mathrm{com} / 2010 / 03 /$ negro-ou-branco-cotasquem-pode-e-quem.html. Acesso em: $16 / 09 / 2018$.

Figura 4 - Capa de revista 2.

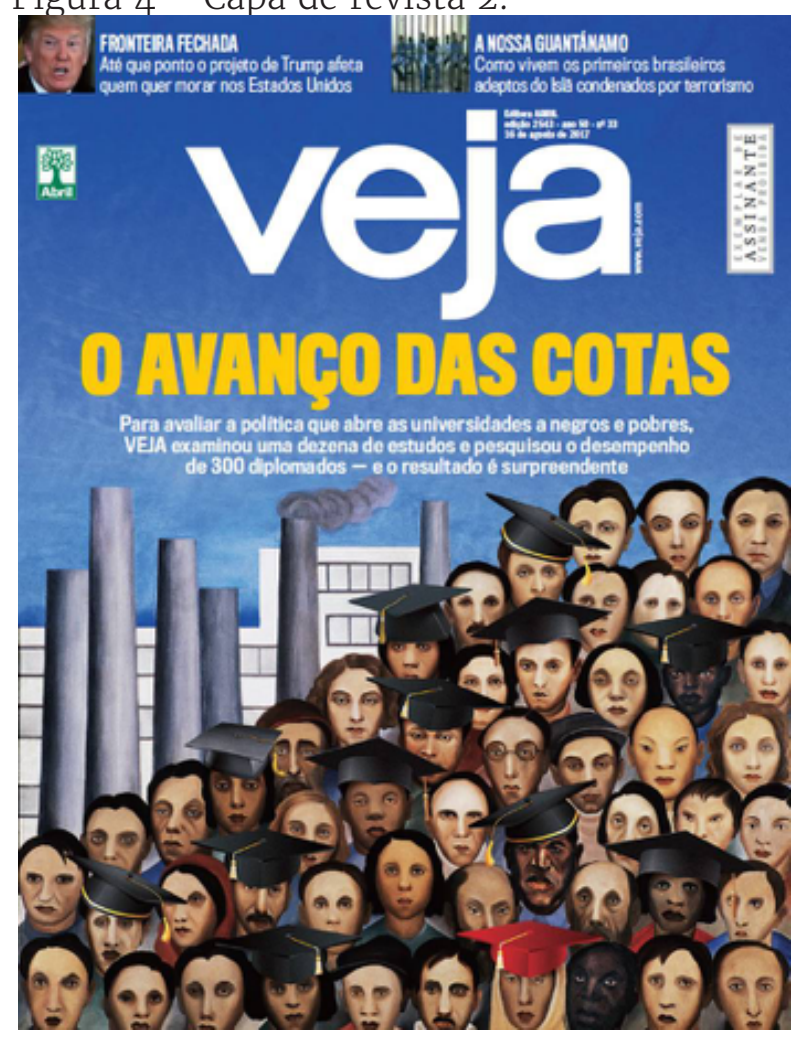

Fonte: https://veja.abril.com.br/edicoesveja/2543/. Acesso em: 16/09/2018. 
v. 9 (1) 72-92 jan-abr 2019

As figuras 3 e 4 contêm capas da revista Veja, uma publicada em 2007 (figura 3) e a outra em 2017 (figura 4). Pelas letras em destaque na cor amarela, depreende-se que a figura 3 é contra ("Raça não existe"), enquanto a figura 4 é a favor das cotas ("O avanço das cotas").

$\mathrm{Na}$ análise da figura 3 feita pelos alunos, foram levantadas as seguintes observações: 1) a revista se posiciona contra, pois esta se aproveita de um caso isolado em que o sistema de cotas não foi bem aplicado para desmerecer a utilidade dele; 2) a capa da figura 3 apresenta tom irônico; 3) a imagem questiona o fato de dois irmãos, gêmeos idênticos, terem sido considerados branco e negro pelo sistema de cotas.

Com relação à figura 4, eles disseram que: 1) a revista se posiciona a favor, pois mostra dados que comprovam a eficiência do sistema de cotas; 2) tanto na parte verbal quanto na imagem é possível observar que há muitos negros que se formaram através do sistema de cotas; 3) os termos "avanço" e "resultado surpreendente" demonstram uma visão positiva sobre o assunto.

Alguns detalhes foram complementados posteriormente com os alunos, mostrando que as cores das camisas dos rapazes, o fato de eles estarem na mesma posição e o plano de fundo da revista dividido em duas cores na figura 3 (parte visual) reforçam a ideia expressa pela parte verbal ("gêmeos idênticos [...] foram considerados [...] branco e negro"; "é mais uma prova de que raça não existe"). Da mesma forma, coube destacar que a imagem na capa da figura 4 faz uma paródia com a tela "Operários", de Tarsila do Amaral, colocando nas pessoas chapéus de formatura. Segundo a revista, na carta ao leitor, a pintura

retrata a enorme diversidade étnica dos brasileiros que chegavam aos magotes para trabalhar nas fábricas de São Paulo nos anos 30. Hoje, mais de oito décadas depois, a tela de Tarsila poderia trazer alguns brasileiros humildes usando um chapéu de formatura, para simbolizar que até filhos de operários, em certos casos, podem concluir um curso universitário. ${ }^{4}$

Aqui se encontra apenas uma parte das atividades realizadas com os alunos. Após a discussão teórica e a análise de alguns textos verbo-visuais, eles afirmaram que, apesar de estarem rodeados a todo momento de charges, propagandas, capas de revistas e jornais, quadrinhos etc., nunca tinham percebido o quanto a imagem fala e pode complementar o que diz a parte verbal; nem quantas coisas implícitas e subentendidas há para se observar em tais textos.

4 Disponível em: https://veja.abril.com.br/revista-veja/carta-ao-leitor-retrato-do-brasil/. Acesso em: 10/10/2018. 
Com isso, pretendemos demonstrar o quanto o letramento em textos multimodais faz-se necessário. Além de, em provas oficiais e nos livros didáticos, os textos verbo-visuais se fazerem presentes, os alunos estão imersos em um mundo cada vez mais imagético, tecnológico. Dessa forma, ao trabalhar habilidades que ampliem a leitura de mundo deles e que os façam ter um olhar mais "aguçado", estaremos contribuindo para que os argumentos e as teses subjacentes em tais textos midiáticos não sejam ignorados, capacitando-os para pensar por si mesmos de forma crítica, e cabendo a eles concordar ou não com aquilo que lhes é sugerido.

\section{Considerações finais}

Conforme foi exposto neste trabalho, o entendimento da relação leitura/escrita mostra que a escola deve diversificar as práticas de leitura e produção textual, oferecendo situações que estejam relacionadas às diferentes necessidades de uso da linguagem, assim como acontece na vida cotidiana, além de promover a reflexão sobre os diversos gêneros e usos da língua, sejam eles orais ou escritos.

Acreditamos que, por meio do desenvolvimento da capacidade argumentativa, torna-se possível aprofundar a própria reflexão acerca do mundo e promover a troca de ideias com outros. Em outras palavras, significa assegurar a liberdade de pensar e de expressar o pensamento. Assim, esperamos ter demonstrado que o trabalho constante e diversificado com a argumentação precisa ter como objetivo final promover a garantia e valorização da autonomia individual de cada aluno numa sociedade que busca ser cada vez mais democrática.

\section{Referências}

AQUINO, Zilda Gaspar Oliveira. Gênero orais, argumentação e ensino de língua portuguesa. Filologia Linguística Portuguesa, São Paulo, v.17, n.1, p.227-248, jan./jun.2015.

BRASIL. Parâmetros Curriculares Nacionais - terceiro e quarto ciclos do ensino fundamental: língua portuguesa. Brasília: MEC/SEF, 1998.

CAGNIN, Antonio Luiz. Os quadrinhos: linguagem e semiótica: um estudo abrangente da arte sequencial. 1 ed. São Paulo: Criativo, 2014.

CASTILHO, Ataliba Teixeira de. A língua falada no ensino de Português. São Paulo: Contexto, 1998. 
v. 9 (1) $72-92$ jan-abr 2019

CASTILHO, Ataliba Teixeira de; BASILIO, Margarida. (org.) Gramática do Português falado. Campinas: Editora da UNICAMP/FAPESP, vol. IV, 1996

CASTILHO, Ataliba Teixeira de; PRETI, Dino (orgs.) A linguagem Falada Culta na cidade de São Paulo. Materiais para estudo. São Paulo: TAQ/Fapesp, vol. 1 , Elocuções Formais, 1986.

CHARAUDEAU, Patrick. Grammaire du sens et de l'expression. Paris, Hachette, 1992.

CHARAUDEAU, Patrick. A argumentação talvez não seja o que parece ser. In.: GIERING, M. E.; TEIXEIRA, M. Investigando a linguagem em uso: estudos em linguística aplicada. São Leopoldo: Ed. Unisinos, 2004. p. 33-44.

CHARAUDEAU, Patrick. Linguagem e discurso: modos de organização. $1^{\mathrm{a}}$ ed., $1^{\mathrm{a}}$ reimpressão. São Paulo: Contexto, 2009.

CHARAUDEAU, Patrick.; MAINGUENEAU, Dominique. Dicionário de Análise do Discurso. São Paulo: Contexto, 2004.

DEMO, Pedro. Conhecer e aprender: sabedoria dos limites e desafios. Artmed: São Paulo, 2000.

GARCEZ, Lucília Helena do Carmo. Técnica de Redação: o que é preciso para bem escrever. $2^{\mathrm{a}}$ ed. São Paulo: Martins Fontes, 2004.

GERALDI, João Wanderley. Portos de passagem. São Paulo: Martins Fontes, 1995.

KOCH, Ingedore Villaça G. (org.) Gramática do Português falado. Campinas: Editora da UNICAMP/FAPESP, vol. vi, 1996

KOCH, Ingedore Villaça G. A inter-ação pela linguagem. $4^{\mathrm{a}}$ ed. São Paulo: Cortez, 1998.

MARCUSCHI, Luiz Antônio. Análise da conversação. São Paulo: Ática, 1986.

MARCUSCHI, Luiz Antônio. Concepção de língua falada nos manuais de português de $1^{\circ}$. e $2^{\circ}$. Graus: uma visão crítica. In: Trabalhos em Linguística Aplicada, 30: 39-79, 1997.

MENEZES, William Augusto. Estratégias discursivas e argumentação. In: LARA, Gláucia Proença (org.). Lingua(gem), texto, discurso: entre a reflexão e a prática, v.1. Rio de Janeiro: Lucena: Belo Horizonte, MG: FALE/UFMG, 2006, p. 87-105. 